\title{
PAPILLARY THYROID CARCINOMA;
} THE FREQUENCY OF MULTIFOCALITY IN PATIENTS UNDERGOING TOTAL THYROIDECTOMY

\section{Dr. Faiza Siddique, Dr. Ahsen Nazir Ahmad, Dr. Ashfaq Ahmad, Dr. Naveed Ahsan, Dr. Tooba Mehmud Gauhar, Dr. Khawaja Muhammad Azim}

ABSTRACT.....At Mayo Hospital Lahore, from August 2010 to April 2011. Objective: was to determine the frequency of multifocality among all cases presented with papillary thyroid carcinoma (PTC) planned to undergo total thyroidectomy (TT). Material \& Methods: Data of all patients of PTC was collected from inpatient department of East Surgical ward. All the patients underwent total thyroidectomy by same team of consultant surgeons. Results: A total of 35 patients of PTC with mean age of 37.94 years were included. Multifocal tumor was found in $31.4 \%$. Out of them, $72.7 \%$ were females and $27.3 \%$ males. This case series showed that a multifocality is highly prevalent in PTC and total thyroidectomy should be done as the treatment for PTC, to eliminate the additional tumor foci in thyroid gland and prevent its recurrence.

Key words: Multifocal papillary thyroid carcinoma, total thyroidectomy.

Article Citation

Siddique F, Ahmad AN, Ahmed A, Ahsan N, Gauhar TM, Azim KM. Papillary thyroid carcinoma; the frequency of multifocality in patients undergoing total thyroidectomy. Professional Med J 2013;20(4): 581-586.

\section{INTRODUCTION}

Thyroid carcinoma is the commonest endocrine cancer that accounts for $92 \%$ of all endocrine malignancies. It represents $1 \%$ to $1.5 \%$ of all malignancies in adults and $3 \%$ in children $^{1,2,3}$. It is relatively less common in adolescent and young patients, with the incidence rising rapidly between 15 and 29 years of age, reaching a plateau by the 5 th and 6 th decades ${ }^{4}$. It represents the eighth most common cancer in women, with the females affected at almost three times the rate of $\operatorname{men}^{1,5}$. Despite excellent response to surgery and targeted therapy with radioactive iodine, thyroid carcinoma is the $2^{\text {nd }}$ most common cause of death among endocrine cancers after carcinoma of the ovary ${ }^{1,6,7}$.

Papillary thyroid cancer, derived from follicular epithelium of thyroid gland, is the most common histological subtype of thyroid cancer, occurring in about $80 \%$ of cases ${ }^{1}$. It presents is in the form of a solitary or dominant thyroid swelling, or lateral neck swelling due to cervical lymph node metastasis that occurs in $15 \%$ to $40 \%$ of the cases ${ }^{8,9,10,11}$.

PTC frequently presents as a multifocal process ${ }^{3}$. Multifocal disease is defined when $>1$ focus of PTCs are found in the thyroidectomy specimen ${ }^{12}$. Often, there is a primary tumor that is $>1 \mathrm{~cm}$ and additional microscopic foci measuring $<1 \mathrm{~cm}$ and termed Papillary Thyroid Microarcinomas (PTMC) ${ }^{13}$.

Multifocal PTCs represent a very important issue regarding patient management.6Multifocal PTCs are high risk tumours because they are more aggressive in terms of local and distant metastasis, mortality and tumor recurrence, than unifocal PTCs.6 Multifocal lesion in one lobe is strongly associated with contralateral lobe tumor ${ }^{14}$. PTMCs, otherwise considered relatively indolent tumors, become high risk when they are multifocal ${ }^{15}$. This behavior warrants proper preoperative and post operative diagnosis and aggressive management for multifocal tumors ${ }^{16}$.

In the national literature data regarding multifocal PTC is limited. The aim of current study is to identify frequency of multifocal PTC to see the magnitude of problem. Since multifocality is considered one reason to perform total thyroidectomy for PTC ${ }^{17}$, knowing the magnitude of the problem will help to establish the validity of total thyroidectomy as a valid treatment for PTC. 


\section{OBJECTIVE}

The objective was to determine the frequency of multifocal PTC among all cases presenting with PTC planned to undergo total thyroidectomy.

\section{MATERIALS AND METHODS}

This case series was conducted in East Surgical Ward, mayo hospital Lahore, during a period of 8 months from August 2010 to April 2011.

In this descriptive case series, 35 patients were selected by non probability, consecutive sampling. Inclusion criteria was all patients of age 13 to 70 years of both genders, undergoing total thyroidectomy for PTC diagnosed preoperatively by fine needle aspiration cytology, and cases confirmed as PTC on histopathology after hemithyroidectomy now planned for completion thyroidectomy. Patients who do not consent to be part of study were excluded.

\section{DATA COLLECTION METHOD}

All patients fulfilling the inclusion criteria were selected from inpatient department of Mayo Hospital, Lahore. Informed consent from each patient was taken and ethical considerations were taken care of. Patients underwent total thyroidectomy by same team of consultant surgeons and were assessed for the presence of multifocal PTC on histopathology. Outcome was recorded in pre designed proforma.

\section{DATA ANALYSIS}

Data was analyzed, tabulated and statistical analysis was done using SPSS version 10 .

\section{RESULTS}

Out of a total 35 patients of PCT 26 were females while 9 were males. Male to female ratio was 1:2.8. 29 patients were diagnosed by FNAC preoperatively and they underwent total thyroidectomy, while 6 patients were diagnosed on histopathology of hemithyroidectomy specimen and they subsequently underwent completion thyroidectomy. (Table-I)

\begin{tabular}{|c|c|c|}
\hline Properties & Frequency & Percentages \\
\hline Mean Age & 37.94 & - \\
\hline Gender & 9 & 25.7 \\
\hline Male & 26 & 74.3 \\
\hline Female & 29 & 82.9 \\
\hline Diagnosis & 5 & 14.3 \\
\hline \multicolumn{2}{|c|}{ FNAC } \\
$\begin{array}{c}\text { Histopath of } \\
\text { hemithyroidectmy }\end{array}$ & 1 & 2.9 \\
\hline $\begin{array}{c}\text { FNAC of } \\
\text { lymph node }\end{array}$ & Table-I. Demographic and clinical features of patients \\
in the study (N=35)
\end{tabular}

Out of 35 patients of PTC, 11(31.4\%) had multifocal tumor. (Table-II) (Figure 1, 2)

\begin{tabular}{|c|c|c|}
\hline Tumor type & Frequency & Percent \\
\hline Unifocal PTC & 24 & 68.6 \\
\hline Multifocal PTC & 11 & 31.4 \\
\hline Total & 35 & 100.0 \\
\hline
\end{tabular}

Table-II. Frequency of multifocal PTC among all PTCS ( $n=35$

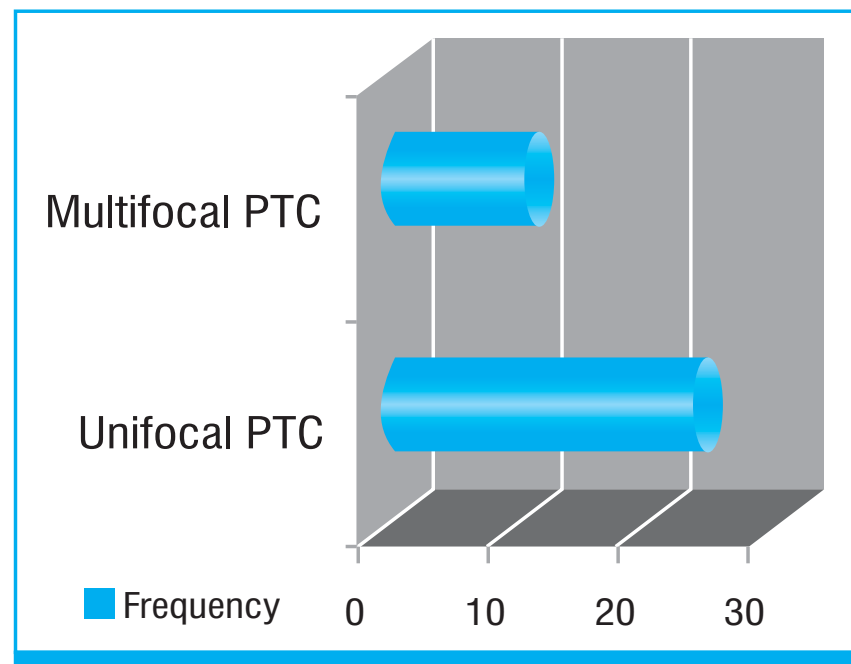

Figure 1: Frequency of multifocal PTC among all PTCs $(n=11)$ 


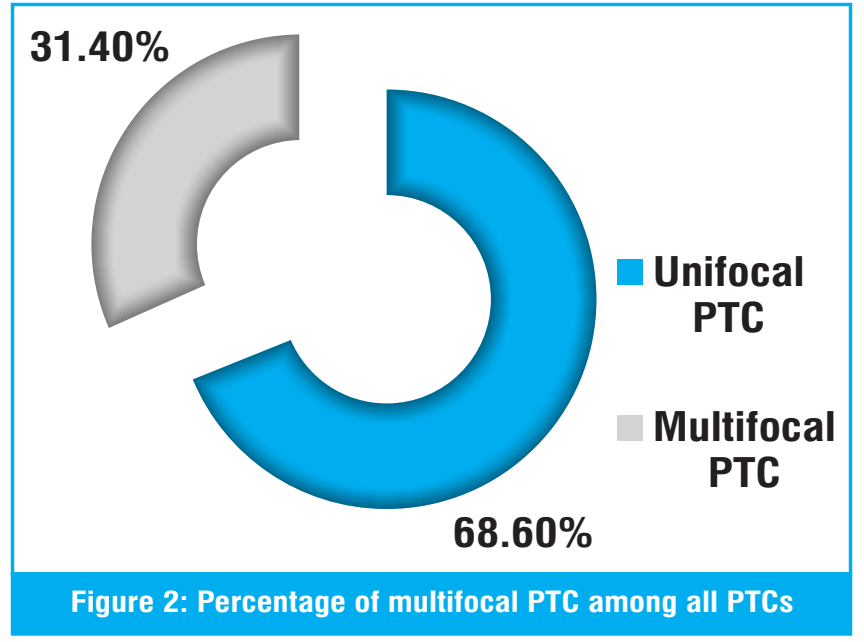

Among patients of multifocal PTC 8 (72.7\%) were females while $3(27.3 \%)$ were males. (Table-III) (Figure 3)

\begin{tabular}{|c|c|c|}
\hline Gender & Frequency & Percent \\
\hline Female & 8 & 72.7 \\
\hline Male & 3 & 27.3 \\
\hline Total & 11 & 100.0 \\
\hline
\end{tabular}

Table-III. Gender distribution among multifocal PTC patients $(n=11)$

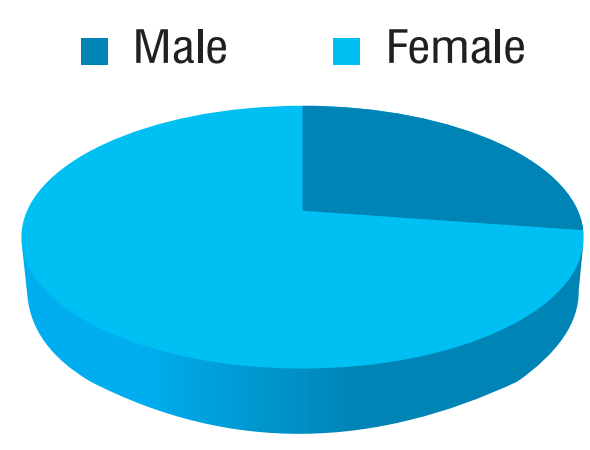

Figure 3: Gender distribution among multifocal PTC patients (Percentages)

Male to female ratio was 1:2.6. But if we compare within the gender, of all females of PTC $30 \%(8 / 26)$ had multifocal PTC while among all males 33\% (3/9) had multifocal disease.

Mean age of presentation of patients with multifocal PTC was 44.5 years $(S D \pm 13.9)$ ranging between 18 and 65 years (Figure 4 ).

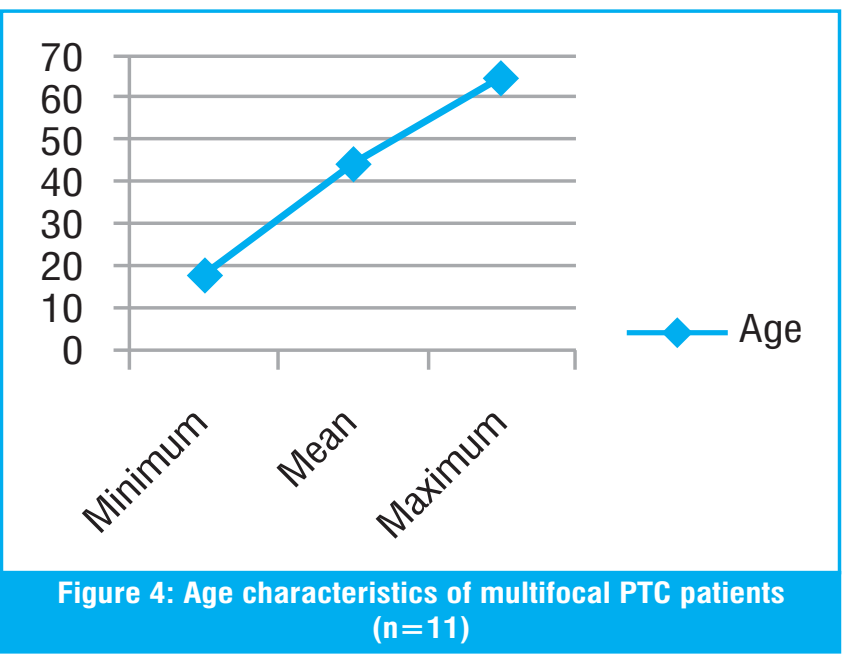

The highest numbers of patients were aged between $41-50$ years $(36.4 \%)(n=4 / 11)$, followed by the ones with age between $31-40$ years $(n=3 / 11)(27.3 \%)$ while 2 patients $(18.2 \%)$ were aged between $61-70$ years, (Figure 5)

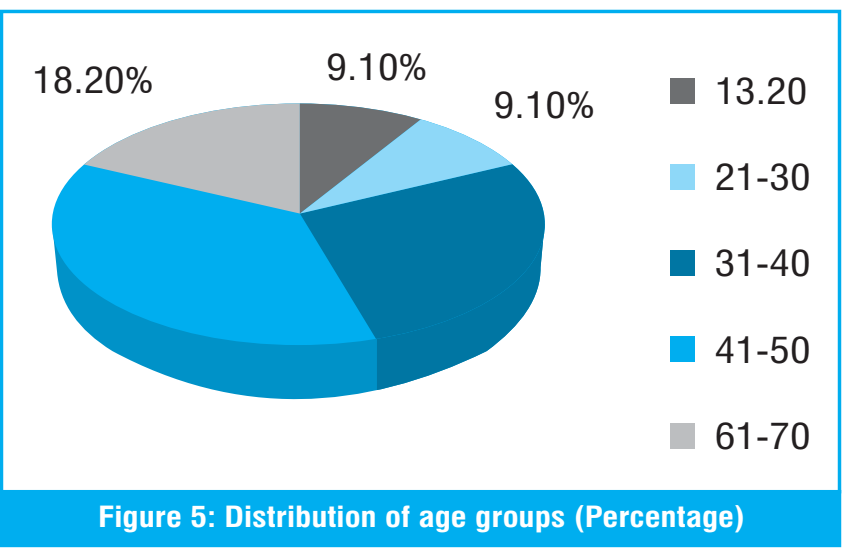

The mean age of presentation was higher for males $(58.33 \pm 11.5)$ as compared to females (39.38 \pm 11.38$)$. (Figure 6) 


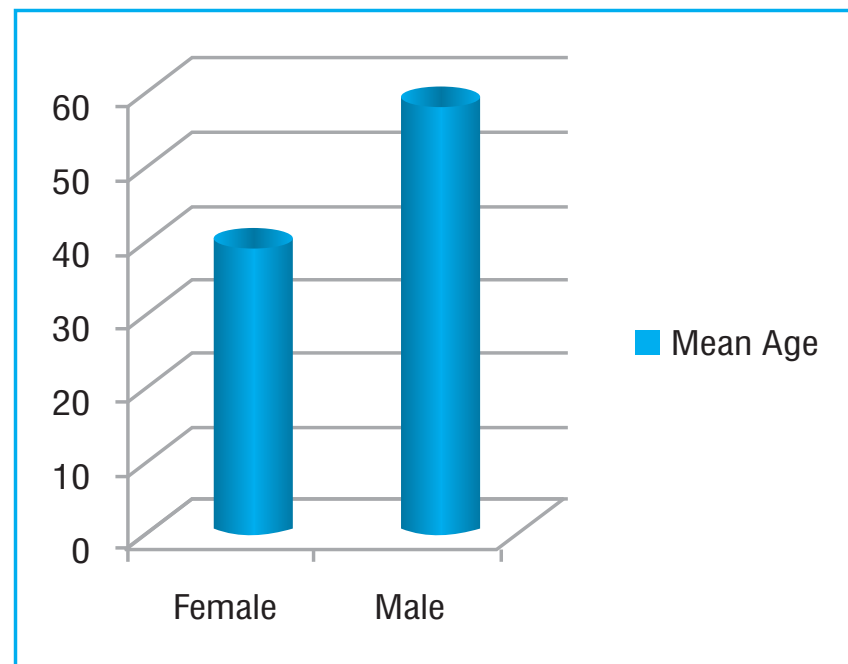

Figure 6: Comparisons of mean ages between males and females

\section{DISCUSSION}

PTC is a well differentiated thyroid carcinoma with an excellent prognosis. Multifocality is quiet common in patients of PTC ${ }^{17}$. Presence of multifocal disease is considered an aggressive form of the tumor due to its association with bad prognostic factors both in microcarcinomas and large PTC ${ }^{6,14}$.

In my study, frequency of multuifocal disease among all PTC's was $31.4 \%$. This frequency is quiet variable in previous studies and in literature reported to range between $18-87 \% \%^{18,19}$. In studies by Lin $\mathrm{JD}^{16}$, Lin YK ${ }^{20}$, Bardet $\mathrm{S}^{21}$ and Zafon $\mathrm{C}^{12}$, the reported incidence is $20 \%, 25 \%, 44 \%$ and $50 \%$ respectively that is consistent with the figures in my study. These studies recommend total thyroidectomy as well as close survillence of patients with multifocal PTC for both large and microcarcinomas ${ }^{16,20}$. However in a study held in Pakistan, by lqbal $\mathrm{M}$ et al, only $6.45 \%$ of PTC was found to have multifocal tumor ${ }^{22}$. In another study by Ullah $\mathrm{N}$ et al, only one patient out of 40 , was found to have multifocal PTC ${ }^{23}$. These two results do not match the international data as well as other Asian studies mentioned above. This might be due to variation in technique employed during histological diagnosis of PTC (large sections cut through the specimen may miss small foci of tumors $)^{16}$. Also, these studies were not conducted to address multifocal disease, thus implicating the need for a pilot study to know the magnitude of the problem.

\section{CONCLUSION}

Multifocality is considered a high risk factor ${ }^{6}$. Due to the commonness of multifocality and poor follow up of the patients, generally, in our culture; total thyroidectomy is to be considered a treatment of choice for PTC. This will eliminate any residual tumor foci in remaining thyroid tissue, which could become a recurrence in future ${ }^{17}$. We recommend that all patients diagnosed preoperatively on FNAC as having PTC or patients diagnosed on histopathology after partial thyroidectomy should undergo total thyroidectomy and completion thyroidectomy respectively.

\section{Copyright@ 02 May, 2013.}

\section{REFERENCES}

1. Al-Brahim N, Asa SL. Papillary thyroid carcinoma: an overview. Arc Path Lab Med $2006 \mathrm{Jul} ; 130(7): 1057-62$.

2. Bukhari U, Sadiq S, Memon JH, Baig F. Thyroid carcinoma--experience at Jinnah Postgraduate Medical Centre Karachi. J Pak Med Assoc. 2010;60(5):365-7.

3. Nistor C, Davidescu M, Ciuche A, Ovidiu, Tudose A, Vasilescu, et al. Giant multifocal thyroid tumor. Maedica A Journal of Clinical Medicine 2009;4(4):346-352.

4. Machens A, Lorenz K, Thanh PN, Brauckhoff $\mathrm{M}$, Dralle H. Papillary thyroid cancer in children and adolescents does not differ in growth pattern and metastatic behavior. Clinical Thyroidology 2010;22(7):9-11.

5. Canchola AJ, Horn-Ross PL, Purdie DM. Risk of second primary malignancies in women with papillary thyroid cancer. Am J Epidemiolo 
2006; 163(6):521-7.

6. Aherne ST, Smyth PC, Flavin RJ, Russell SM, , $\mathrm{Li} \mathrm{JH}$, et al. Geographical mapping of a multifocal thyroid tumour using genetic alteration analysis \& mi RNA profiling. Mol Cancer [online] 2008 Dec [cited 2009 Dec 03];7: Available from: URL: http://www.nc bi.nlm.nih.gov/pmc/articles/PMC2612696/?t ool=pubmed

7. Haq RN, Khan BA, Chaudhry IA. Prevalence of malignancy in goitre-a review of 718 thyroidectomies. J Ayub Med Coll Abbottabad 2009 0ct-Dec;21(4):134-6.

8. Polyzos SA, Kita M, Avramidis A. Thyroid nodules -Stepwise diagnosis and management. Hormones 2007;6(2):101119.

9. Naseeb HK, Khan MR, Rasool G, Ajmal K, Khan F, Naseeb HK et al. Uptake of Tc-99m MIBI for assessment of cold thyroid nodule. PakJ Med Res 2007;46(2):31-36.

10. Thyroid Cancer Watkinson JC, Franklyn JA, Olliff JFC. Detection and surgical treatment of cervical lymph nodes in differentiated thyroid cancer. Thyroid 2006;16(2):187-94.

11. Pazaitou-Panayiotou K, Alevizaki M, Boudina M, Drimonitis A, Kiziridou A, Vainas I. Cervical masses as manifestation of papillary thyroid carcinomas $\leqslant 10 \mathrm{~mm}$ in diameter, in patients with unknown thyroid disease. Thyroid Res [online] 2008 Dec 6 [cited 2009 Dec 03]; Available from: URL:http://pubmedcentral canada.ca/articlerender.cgi?artid $=102507$

12. Zafon C, Baena JA, Castellví J, Obiols G, Monroy G, Mesa J. Differences in the form of presentation between papillary microcarcinomas and papillary carcinomas of larger size. $\mathrm{J}$ Thyroid Res [online] 2010 Dec 14 [cited 2011 Jul 6]; Available from: URL:http://www.hind awi.com/journals/jtr/2011/639156/abs/

13. McCarthy RP, Wang M, Jones TD, Strate RW, Cheng L. Molecular evidence for the same clonal origin of multifocal papillary thyroid carcinomas. Clin Cancer Res 2006 15;12(8):2414-8.

14. Chagas JFS, Aquino JLBD, Pascoal MBN, Teixeira AS, Ferro MMN, Gambaro MCO, et al. Multicentricity in the thyroid differentiated carcinoma. Braz J Otorhinolaryngol 2009;75(1):97-100.

15. Lin X, Finkelstein SD, Zhu B, Silverman JF. Molecular analysis of multifocal papillary thyroid carcinoma. J Mol Endocrinol. 2008;41(4):195-203.

16. Lin JD, Chao TC, Hsueh C, Kuo SF. High recurrent rate of multicentric papillary thyroid Carcinoma. Ann Surg Oncol 2009;16(9): 2609-16.

17. Elaraj DM, Sturgeon C. Adequate surgery for papillary thyroid cancer. The Surgeon 2009;7(5):286-9.

18. Park SY, Park YJ, Lee YJ, Lee HS, Choi SH, Choe $G$, et al. Analysis of differential BRAFV600E mutational status in multifocal papillary thyroid carcinoma: evidence of independent clonal origin in distinct tumor foci. Cancer 2006 15;107(8): 1831-8.

19. Giannini R, Ugolini C, Lupi C, Proietti A, Elisei $R$, Salvatore $G$, et al. The heterogeneous distribution of BRAF mutation supports the 
independent clonal origin of distinct tumor foci in multifocal papillary thyroid carcinoma. J Clin Endocrinol Metab. 2007;92(9):3511-6.

20. Lin YK, Sheng JM, Zhao WH, Wang WB, Yu XF, Teng LS, et al. Multifocal papillary thyroid carcinoma a clinical analysis of 168 cases. Zhonghua wai ke za zhi 2009;47(6):450-3.

21. Bardet S, Malville E, Rame JP, Babin E, Samama G, Raucourt DD, et al. Macroscopic lymph-node involvement and neck dissection predict lymph-node recurrence in papillary thyroid carcinoma. Eur $\mathrm{J}$ Endocrinol. 2008;158(4):551-60.

22. Iqbal M, Mehmood Z, Rasul S, Inamullah, Shah SSH, Bokhari I. Carcinoma thyroid in multi and uninodular goiter. Coll Physicians Surg Pak. 2010;20(5):310-2.

23. Ullah N, Khan Q, Said M, Afridi HR, Ahmad N. Completion thyroidectomy for differentiated thyroid carcinoma. JPMI 2009; 23(1):70-73.

\section{AUTHOR(S):}

1. DR. FAIZA SIDDIQUE

Senior Registrar General Surgery

Sharif Medical and Dental College, Lahore.

2. DR. AHSEN NAZIR AHMAD

Associate Professor General Surgery

Sharif Medical and Dental College, Lahore.

3. DR. ASHFAQ AHMAD

Associate Professor General Surgery

Mayo Hospital, Lahore

4. Dr. Naveed Ahsan

Post Graduate Trainee Medical Oncology

Oncology Department,

Jinnah Hospital, Lahore
5. Dr. Tooba Mehmud Gauhar

Senior Registrar General Surgery

Mayo Hospital, Lahore

6. Dr. Khawaja Muhammad Azim

Professor of General Surgery

Mayo Hospital, Lahore

Correspondence Address:

Dr. Faiza Siddique

Senior Registrar General Surgery

Sharif Medical and Dental College, Lahore.

drfaizasiddique@yahoo.com

Article received on: 18/01/2013 Accepted for Publication: 02/05/2013 Received after proof reading: $21 / 05 / 2013$

\section{People have been known to achieve more as a result of working with others than against them.}

Dr. Allan Fromme 